\title{
Chemical diffusion and oxygen exchange of $\mathrm{LaNi}_{0.4} \mathrm{Fe}_{0.6} \mathrm{O}_{3-\delta}$ ceramics
}

\author{
Jianying CHEN ${ }^{a, b, e, *}$, Vladimir VASHOOK ${ }^{b}$, Dmytro M. TROTS ${ }^{c}$, \\ Shaorong $\mathrm{WANG}^{a}$, Ulrich GUTH ${ }^{b, d}$ \\ ${ }^{a}$ Chinese Academy of Sciences, 1295 Dingxi Road, Shanghai 200050, China \\ ${ }^{b}$ Dresden University of Technology, D-01062 Dresden, Germany \\ ${ }^{c}$ Bayerisches Geoinstitut, Universität Bayreuth, D-95440 Bayreuth, Germany \\ ${ }^{d}$ Meinsberg Kurt-Schwabe Research Institute, Kurt-Schwabe-Straße 4, D-04720 Ziegra-Knobelsdorf, Germany \\ ${ }^{e}$ Shanghai Nanotechnology Promotion Center, Shanghai, China
}

Received: April 09, 2014; Revised: June 19, 2014; Accepted: June 22, 2014

CThe Author(s) 2014. This article is published with open access at Springerlink.com

\begin{abstract}
Oxygen surface exchange and oxygen chemical diffusion coefficients of $\mathrm{LaNi}_{0.4} \mathrm{Fe}_{0.6} \mathrm{O}_{3-\delta}$ ceramics are determined via conductivity relaxation method after stepwise change of temperature in the range of $700-950{ }^{\circ} \mathrm{C}$ in air and $\mathrm{Ar} / \mathrm{O}_{2}$ gas flow at oxygen partial pressures $\left(p_{\mathrm{O}_{2}}\right)$ of $4 \mathrm{~Pa}, 18 \mathrm{~Pa}$, $37 \mathrm{~Pa}, 47 \mathrm{~Pa}$ and $59 \mathrm{~Pa}$. The highest conductivity (about $160 \mathrm{~S} \cdot \mathrm{cm}^{-1}$ ) is found at $950{ }^{\circ} \mathrm{C}$ in air. No oxygen exchange $(\delta=0)$ below $700{ }^{\circ} \mathrm{C}$ is observed in the investigated $p_{\mathrm{O}_{2}}$ range. The oxygen exchange coefficients determined in reduction mode are higher than those determined in oxidation mode. This is explained by clusterization of oxygen vacancies on the surface of the sample investigated in oxidation mode. The opposite tendency is found for chemical diffusion coefficients. Unlike surface, the oxygen vacancies of the volume region are probably not clustered and have predetermined the higher oxygen diffusion mobility of the sample treated in oxidation mode.
\end{abstract}

Keywords: oxygen non-stoichiometry; conductivity; chemical diffusion coefficient; surface exchange coefficient

\section{Introduction}

The development of intermediate temperature solid state fuel cell (IT-SOFC) is now gathering much attention as it offers several advantages over conventional power generation systems, notably, the ability to use carbon monoxide as a fuel and the possibility of cogeneration with gas turbine power systems to achieve optimal efficiency. An important issue for the development of SOFC is the selection of appropriate electrode materials [1]. The cathode materials are the key factor to improve the

* Corresponding author.

E-mail: chen-clara@hotmail.com performance of SOFC. $\mathrm{LaNi}_{1-x} \mathrm{Fe}_{x} \mathrm{O}_{3-\delta}$ materials satisfy the important requirements for $\mathrm{SOFC}$ cathode [2]. Zhen et al. [3] reported that $\mathrm{LaNi}_{0.6} \mathrm{Fe}_{0.4} \mathrm{O}_{3-\delta}$ cathode has high tolerance to chromium poisoning in SOFC. Orui et al. [4] developed a SOFC stack with $\mathrm{LaNi}_{0.6} \mathrm{Fe}_{0.4} \mathrm{O}_{3-\delta}$ as cathode material. $\mathrm{LaNi}_{0.6} \mathrm{Fe}_{0.4} \mathrm{O}_{3-\delta}$ composition has low reactivity to yttria-stabilised zirconia $[5,6]$ and the highest electronic conductivity in $\mathrm{LaNi}_{1-x} \mathrm{Fe}_{x} \mathrm{O}_{3-\delta}$ series. As cathode material it shows one of the lowest cell over-potentials at $800{ }^{\circ} \mathrm{C}$ [7-9].

To create high performance electrode, mixed conductors with high ionic and electronic conductivities should be utilized [10]. Important features of these materials (mixed conductors) are their ability to absorb or desorb oxygen reversibly without 
change in crystal structure and their high oxygen diffusivity. Reports on the oxygen diffusion and surface exchange coefficients obtained with mixed conductors have been made by different researchers [11-13]. The rate of absorption/desorption is governed by bulk oxygen anion and electron transport, as well as catalytic reduction/oxidation of oxygen at the surface [14]. The necessary requirements for the application of mixed ionic and electronic conducting materials in SOFC are the rapid incorporation of oxygen from gas phase and its fast transport in the bulk of the materials to the phase boundary with the solid electrolyte. Then understanding the transport mechanism of oxygen through the electrode materials and the experimental parameters, such as oxygen surface exchange and chemical diffusion coefficients, provides useful information for selecting new promising electrode materials [15]. Unfortunately, no data of oxygen mobility and oxygen exchange kinetics is published for $\mathrm{LaNi}_{1-x} \mathrm{Fe}_{x} \mathrm{O}_{3-\delta}$ compositions until now.

This article aims to investigate the relation between oxygen non-stoichiometry and electrical conductivity and to determine the oxygen surface exchange and chemical diffusion coefficients for $\mathrm{LaNi}_{0.4} \mathrm{Fe}_{0.6} \mathrm{O}_{3-\delta}$ ceramics, as one of the poorly investigated compositions in $\mathrm{LaNi}_{1-x} \mathrm{Fe}_{x} \mathrm{O}_{3-\delta}$ series.

\section{Experimental}

\subsection{Sample preparation and diffraction studies}

$\mathrm{LaNi}_{0.4} \mathrm{Fe}_{0.6} \mathrm{O}_{3-\delta}$ powder was prepared by conventional solid state reaction method. $\mathrm{La}_{2} \mathrm{O}_{3}(>99.9 \%), \mathrm{NiO}(>$ $99 \%)$ and $\mathrm{Fe}_{2} \mathrm{O}_{3}(>99 \%)$ powder with appropriate ratio was ground in a planetary mill in ethanol for $24 \mathrm{~h}$ and then sintered at $1250{ }^{\circ} \mathrm{C}$ for $24 \mathrm{~h}$ in air to produce $\mathrm{LaNi}_{0.4} \mathrm{Fe}_{0.6} \mathrm{O}_{3-\delta}$ powder.

The dense ceramic sample (size of $8.5 \mathrm{~mm} \times 2.5 \mathrm{~mm}$ $\times 1.3 \mathrm{~mm}$, density of $94 \%)$ with four Pt wires $(0.1 \mathrm{~mm}$ in diameter) for investigation of oxygen diffusion mobility and oxygen surface exchange was sintered in air at $1600{ }^{\circ} \mathrm{C}$ for $17 \mathrm{~h}$. No decomposition of the compound by X-ray diffraction (XRD) method was registered.

In situ structural studies on $\mathrm{LaNi}_{0.4} \mathrm{Fe}_{0.6} \mathrm{O}_{3-\delta}$ sample were performed at the synchrotron facility HASYLAB/DESY (Hamburg, Germany) with the powder diffractometer at beam-line B2 [16]. The sample was ground in the agate mortar and sieved through a mesh. The $0.3 \mathrm{~mm}$ quartz capillary was filled under air atmosphere with powdered sample and sealed. Subsequently the capillary was mounted inside a STOE furnace in Debye-Scherrer geometry, equipped with a Eurotherm temperature controller and a capillary spinner. The furnace temperature was measured by TYPE-N thermocouple. A wavelength of $0.65125 \AA$ was selected using a $\mathrm{Si}(111)$ double flat-crystal monochromator from the direct white synchrotron beam. The X-ray wavelength was determined from eight reflection positions of $\mathrm{LaB}_{6}$ reference material (NIST SRM 660a) measured by scintilation single counter detector. The 10 diffraction patterns were collected (9-12 min per pattern in dependence on the synchrotron current) at fixed temperatures in the range of $298-1173 \mathrm{~K}$ ( 2 min for temperature stabilization) during the heating cycles using an image-plate detector $\left(2 \theta\right.$ range of $8^{\circ}-60^{\circ}$ ). One additional check-pattern was taken at ambient temperature after the heat treatment. All diffraction patterns were analyzed by full-profile Rietveld refinements using the program package WinPLOTR/FullProf.

\section{2 Conductivity and oxygen content measurement}

Oxygen content was investigated on the powder, and electrical conductivity was measured on dense sample by a solid electrolyte measurement complex ZiroxSystem (Zirox, Greifswald, Germany), which is analogous to OXYLYT complex described elsewhere [17] (Fig. 1). The concept of a combined coulometric-potentiometric arrangement for investigation of the interactions between solid and the

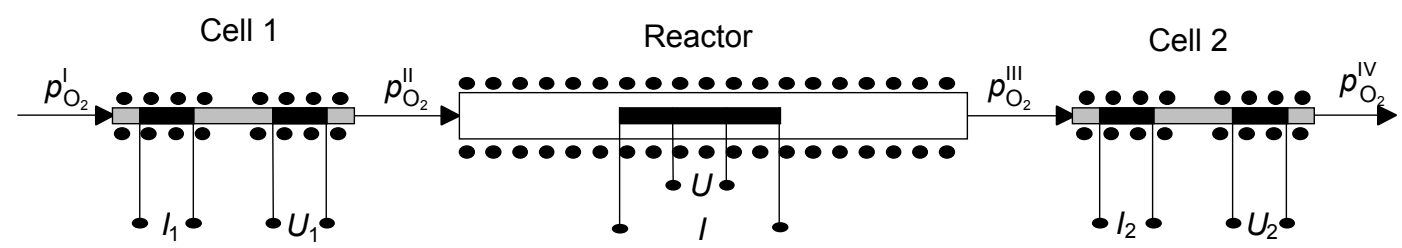

Fig. 1 Scheme of a solid electrolyte measurement complex ZiroxSystem (Greifswald, Germany). 
gaseous environment in the carrier gas was described elsewhere [18].

A four-point direct current method was used for conductivity measurements in air and in $\mathrm{Ar} / \mathrm{O}_{2}$ gas flow at oxygen partial pressure of $4-59 \mathrm{~Pa}$ and temperature of $700-950{ }^{\circ} \mathrm{C}$. The conductivity was recalculated for theoretical density of samples using the equation:

$$
\sigma_{\mathrm{d}}=\sigma_{\mathrm{p}} \times \frac{1+p / 2}{(1-p)^{2 / 3}}
$$

where $p$ is the relative porosity; $\sigma_{\mathrm{d}}$ and $\sigma_{\mathrm{p}}$ are the conductivities of dense and porous samples, respectively [19].

\section{3 Oxygen diffusion mobility and oxygen surface exchange}

Oxygen chemical diffusion and oxygen surface exchange coefficients were determined by conductivity measurements of the dense sample after $50 \mathrm{~K}$ upward (reduction) and downward (oxidation) temperature jumps from one equilibrium state to another at the temperature rate of $40 \mathrm{~K} \cdot \mathrm{min}^{-1}$. Relaxation measurements were carried out in $\mathrm{Ar} / \mathrm{O}_{2}$ gas flow at the oxygen partial pressures of $4 \mathrm{~Pa}, 18 \mathrm{~Pa}, 37 \mathrm{~Pa}, 47 \mathrm{~Pa}$ and $59 \mathrm{~Pa}$.

The analysis of the results of relaxation measurements was carried out using the solution of Fick's second law for a rectangular sample with the dimensions of $2 h \times 2 w \times 2 l$ by the following equation $[20,21]$ :

$$
\begin{aligned}
& \frac{\sigma_{t}-\sigma_{0}}{\sigma_{\infty}-\sigma_{0}}=1-\sum_{i=1}^{\infty} \sum_{m=1}^{\infty} \sum_{n=1}^{\infty} \frac{2 L_{1}^{2} \exp \left(-\beta_{i}^{2} \tilde{D}_{\mathrm{O}} t / h^{2}\right)}{\beta_{i}^{2}\left(\beta_{i}^{2}+L_{1}^{2}+L_{1}\right)} \\
& \times \frac{2 L_{2}^{2} \exp \left(-\gamma_{m}^{2} \tilde{D}_{\mathrm{O}} t / w^{2}\right)}{\gamma_{m}^{2}\left(\gamma_{m}^{2}+L_{2}^{2}+L_{2}\right)} \times \frac{2 L_{3}^{2} \exp \left(-\delta_{n}^{2} \tilde{D}_{\mathrm{O}} t / l^{2}\right)}{\delta_{n}^{2}\left(\delta_{n}^{2}+L_{3}^{2}+L_{3}\right)}
\end{aligned}
$$

where $t$ is the diffusion time; $\sigma_{0}, \sigma_{\infty}$ and $\sigma_{t}$ denote the conductivities at $t=0$ (initial), $t=\infty$ (after reaching a new equilibrium state) and time $t$ (in the course of a relaxation), respectively; and $\tilde{D}_{\mathrm{O}}$ is the chemical diffusion coefficient. The dimensionless parameters $L_{1}, L_{2}$ and $L_{3}$ are defined using the linear oxygen exchange rate constant $(\alpha)$ and the chemical diffusion coefficient $\left(\tilde{D}_{\mathrm{O}}\right)$ :

$$
\begin{aligned}
& L_{1}=h \alpha / \tilde{D}_{\mathrm{O}} \\
& L_{2}=w \alpha / \tilde{D}_{\mathrm{O}} \\
& L_{3}=l \alpha / \tilde{D}_{\mathrm{O}}
\end{aligned}
$$

$$
\begin{aligned}
& \beta_{i} \tan \beta_{i}=L_{1} \\
& \gamma_{m} \tan \gamma_{m}=L_{2} \\
& \delta_{n} \tan \delta_{n}=L_{3}
\end{aligned}
$$

which serve as an appropriate measure of the significance of the surface reaction. Large and small $L$ values correspond to diffusion-controlled and surface-reaction-controlled processes, respectively. $\beta_{i}, \gamma_{m}$ and $\delta_{n}$ are the $n$th roots of Eqs. (6-8), respectively; $2 h, 2 w$ and $2 l$ are thickness, width and length of the sample with rectangular geometry, respectively.

This model of calculation is based on the following restrictions [21]:

(I) At small changes of oxygen nonstoichiometry (approximately 0.01 of the oxygen index), the diffusion parameters are assumed to be independent with composition, i.e., the sample is assumed to maintain its composition within the whole volume before and after the step.

(II) The mobility of the charge carrier can be approximated as constant during the course of relaxation.

(III) A linear relation should be assumed between the changes of the electrical conductivity and the concentration of the lattice oxygen or the oxygen vacancies.

(IV) The surface reaction kinetics is linear with respect to the oxygen concentration at the surface.

(V) The polycrystalline sample is assumed to be isotropic.

(VI) The value of the diffusion coefficient is related to the final temperature after each step.

The accuracy of the relaxation measurements is limited by (1) the errors in the measurement of the geometrical dimensions of the sample; (2) the different ceramic microstructure of sample as a result of difference in preparation of ceramic powder and pressing and sintering conditions; and (3) the experimental uncertainty of a "dead time" after the temperature leap caught up by the sample.

\section{Results and discussion}

\section{1 High temperature structure behavior}

The inspection of systematic absences of Bragg reflections in the synchrotron powder diffraction patterns of perovskite structured $\mathrm{LaNi}_{0.4} \mathrm{Fe}_{0.6} \mathrm{O}_{3-\delta}$ at 
room temperature (RT) reveals orthorhombic symmetry based on the Pbnm space group. The compound undergoes $P b n m \leftrightarrow R \overline{3} c$ transformation at 200-300 ${ }^{\circ} \mathrm{C}$. The observed transition is abrupt with a large volume change and occurs through two phase $(P b n m+R \overline{3} c)$ regions, which is an evidence for the 1st order transition. Figure 2 illustrates the results of Rietveld refinements for the powder with nominal composition $\mathrm{LaNi}_{0.4} \mathrm{Fe}_{0.6} \mathrm{O}_{3-\delta}$ at room temperature and $1173 \mathrm{~K}$. Temperature dependencies of normalized lattice parameters of $\mathrm{LaNi}_{0.4} \mathrm{Fe}_{0.6} \mathrm{O}_{3-\delta}$ are presented in Fig. 3, and the structural parameters are summarized in Tables 1 and 2 .

One additional diffraction check-pattern was taken at room temperature after the heat treatment. The difference in volume after and before heating lies only within estimated standard deviation which indicates that the sample returns to its initial state. Thus, the reversibility of $P b n m \leftrightarrow R \overline{3} c$ transition in $\mathrm{LaNi}_{0.4} \mathrm{Fe}_{0.6} \mathrm{O}_{3-\delta}$ and the stability of the sample in the temperature range of $298-1173 \mathrm{~K}$ are proved. Any phase transitions in the temperature range of $700-900{ }^{\circ} \mathrm{C}$ in air are not observed, and the lattice parameters of the compound have increased linearly with temperature.

Another distinct feature of $\mathrm{LaNi}_{0.4} \mathrm{Fe}_{0.6} \mathrm{O}_{3-\delta}$ is highly anisotropic thermal expansion, particularly in the highest conductivity rhombohedral phase, with lattice $c$ parameter showing larger temperature response than $a$ parameter. Such anisotropy might lead to different expansion of neighboring grains within ceramic sample and, consequently, to stresses at the grain boundaries. Therefore, thermal expansion anisotropy and the 1 st order $P b n m \leftrightarrow R \overline{3} c$ phase transition should be accounted at the design of SOFC cathode.

\section{2 Conductivity and oxygen content measurement}

Influence of stepwise temperature change on time dependencies of titration current in coulometric cell 2 of a ZiroxSystem device and electrical conductivity of the dense $\mathrm{LaNi}_{0.4} \mathrm{Fe}_{0.6} \mathrm{O}_{3-\delta}$ ceramic sample at $p_{\mathrm{O}_{2}}=$ $47 \mathrm{~Pa}$ is presented in Fig. 4(a), whereas Fig. 4(b) presents the analogous time dependencies for titration current and oxygen content of the powder sample at $p_{\mathrm{O}_{2}}=59 \mathrm{~Pa}$. A coincidence of conductivity of sample for the same temperatures at heating and cooling processes is observed in $\mathrm{Ar} / \mathrm{O}_{2}$ gas flow at $p_{\mathrm{O}_{2}}=47 \mathrm{~Pa}$
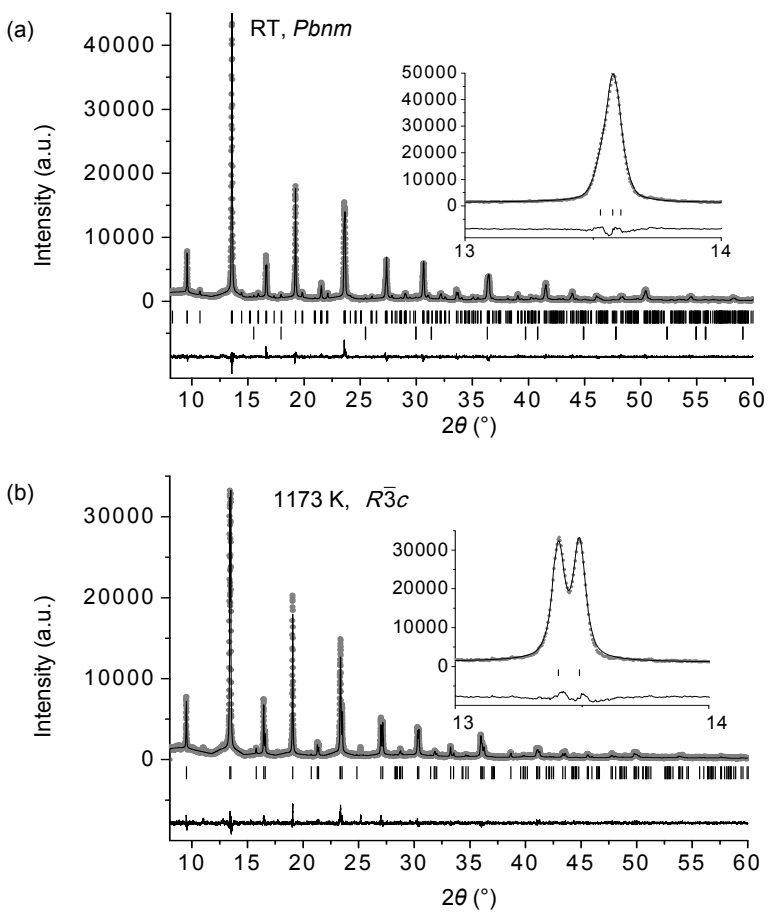

Fig. 2 Results of Rietveld refinements for $\mathrm{LaNi}_{0.4} \mathrm{Fe}_{0.6} \mathrm{O}_{3-\delta}$ at (a) room temperature (Pbnm symmetry) and (b) $1173 \mathrm{~K}$ ( $R \overline{3} c$ symmetry). Dots are experimental data, the lines through the dots are calculated profiles, and the lower plots their difference. Ticks show the calculated positions of Bragg reflections. Upper and lower rows of reflection marks in the room temperature pattern belong to $\mathrm{LaNi}_{0.4} \mathrm{Fe}_{0.6} \mathrm{O}_{3-\delta}($ Pbnm $)-99.4 \%$ and $\mathrm{NiO}$ $(R \overline{3} m)-0.6 \%$, respectively (because of such negligible amount of $\mathrm{NiO}$ impurity, we do not include this phase into refinements of high temperature diffraction data).

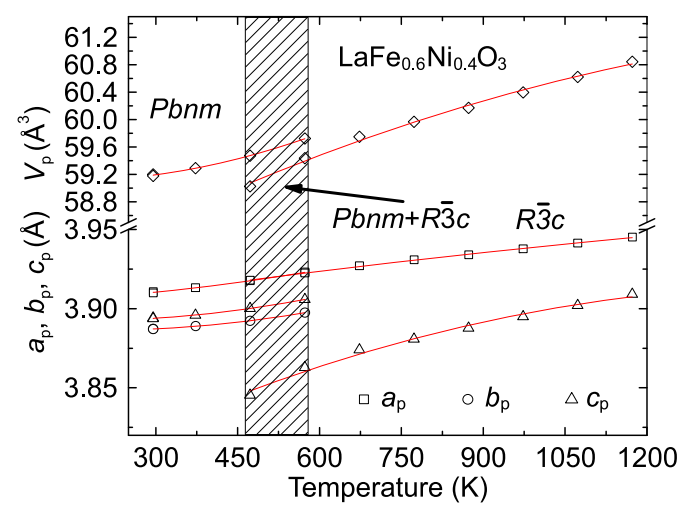

Fig. 3 Temperature dependencies of lattice parameters in $\mathrm{LaNi}_{0.4} \mathrm{Fe}_{0.6} \mathrm{O}_{3-\delta}$. Cell dimensions of orthorhombic phase and rhombohedral polymorphs are normalized as $a_{\mathrm{p}}=a / 2^{0.5}, b_{\mathrm{p}}=b / 2^{0.5}, c_{\mathrm{p}}=c / 2, V_{\mathrm{p}}=V / 4$ and $a_{\mathrm{p}}=a / 2^{0.5}, c_{\mathrm{p}}=c / 12^{0.5}, V_{\mathrm{p}}=V / 6$, respectively. 
Table 1 Structural parameters of $\mathrm{LaNi}_{0.4} \mathrm{Fe}_{0.6} \mathrm{O}_{3-\delta}$ at selected temperatures

\begin{tabular}{|c|c|c|c|c|c|}
\hline Temperature $(\mathrm{K})$ & 298 & \multicolumn{2}{|c|}{573} & \multirow{2}{*}{$\begin{array}{c}873 \\
R \overline{3} c\end{array}$} & \multirow{2}{*}{$\frac{1173}{R \overline{3} c}$} \\
\hline Symmetry & Pbnm & Pbnm & $R \overline{3} c$ & & \\
\hline Fraction (\%) & 100 & $67(1)$ & $33(1)$ & 100 & 100 \\
\hline$a(\AA)$ & $5.5294(1)$ & $5.5481(2)$ & $5.5473(3)$ & $5.5636(1)$ & $5.5793(2)$ \\
\hline$b(\AA)$ & $5.4972(1)$ & $5.5119(2)$ & - & - & - \\
\hline$c(\AA)$ & $7.7873(2)$ & $7.8117(3)$ & $13.3812(4)$ & $13.4676(2)$ & $13.5416(3)$ \\
\hline \multirow[t]{2}{*}{$V\left(\AA^{3}\right)$} & $236.71(1)$ & $238.89(2)$ & $356.61(2)$ & $361.02(1)$ & $365.06(1)$ \\
\hline & \multicolumn{2}{|c|}{ La at 4(c) } & \multicolumn{3}{|c|}{ La at 6(a) } \\
\hline$x / a$ & $0.0029(5)$ & $0.0027(8)$ & 0 & 0 & 0 \\
\hline$y / b$ & $0.0209(1)$ & $0.0178(3)$ & 0 & 0 & 0 \\
\hline$z / c$ & $1 / 4$ & $1 / 4$ & $1 / 4$ & $1 / 4$ & $1 / 4$ \\
\hline \multirow[t]{2}{*}{$U_{\text {iso }}\left(\AA^{2}\right)$} & $0.0168(2)$ & $0.0236(4)$ & 0.02 & $0.0286(3)$ & $0.0345(3)$ \\
\hline & \multicolumn{2}{|c|}{$\mathrm{Fe} / \mathrm{Ni}$ at $4(\mathrm{~b})$} & \multicolumn{3}{|c|}{$\mathrm{Fe} / \mathrm{Ni}$ at $6(\mathrm{~b})$} \\
\hline$x / a$ & $1 / 2$ & $1 / 2$ & 0 & 0 & 0 \\
\hline$y / b$ & 0 & 0 & 0 & 0 & 0 \\
\hline$z / c$ & 0 & 0 & 0 & 0 & 0 \\
\hline \multirow[t]{2}{*}{$U_{\text {iso }}\left(\AA^{2}\right)$} & $0.0144(3)$ & $0.0185(5)$ & 0.02 & $0.0203(4)$ & $0.0232(5)$ \\
\hline & \multicolumn{2}{|c|}{ O1 at 4(c) } & \multicolumn{3}{|c|}{ O1 at $18(\mathrm{e})$} \\
\hline$x / a$ & $0.568(3)$ & $0.588(4)$ & 0.546 & $0.556(1)$ & $0.558(1)$ \\
\hline$y / b$ & $-0.004(2)$ & $0.011(3)$ & 0 & 0 & 0 \\
\hline$z / c$ & $1 / 4$ & $1 / 4$ & $1 / 4$ & $1 / 4$ & $1 / 4$ \\
\hline$U_{\text {iso }}\left(\AA^{2}\right)$ & $0.006(1)$ & $0.008(2)$ & 0.02 & $0.017(2)$ & $0.023(2)$ \\
\hline \multicolumn{6}{|c|}{$\mathrm{O} 2$ at $8(d)$} \\
\hline$x / a$ & $0.781(2)$ & $0.785(3)$ & & & \\
\hline$y / b$ & $0.216(2)$ & $0.223(3)$ & & & \\
\hline$z / c$ & $-0.040(1)$ & $-0.035(2)$ & & & \\
\hline$U_{\text {iso }}\left(\AA^{2}\right)$ & $0.006(1)$ & $0.008(2)$ & & & \\
\hline$R_{\mathrm{Bragg}}, R_{\mathrm{F}}, \chi^{2}$ & $6.2,6.4,15.4$ & $6.7,8.1,16.3$ & $7.0,6.8,16.3$ & $6.8,7.8,16.0$ & $6.5,9.1,16.4$ \\
\hline
\end{tabular}

Occupancy was fixed corresponding to the sample's stoichiometry. Diffraction pattern of the sample revealed traces of rhombohedral $\mathrm{NiO}$ (less than 1\%) which were neglected in the final analysis.

Table 2 Absolute cell dimensions of $\mathrm{LaNi}_{0.4} \mathrm{Fe}_{0.6} \mathrm{O}_{3-\delta}$

\begin{tabular}{ccccc}
\hline $\begin{array}{c}\text { Temperature } \\
(\mathrm{K})\end{array}$ & $a(\AA)$ & $b(\AA)$ & $c(\AA)$ & $V\left(\AA^{3}\right)$ \\
\hline 298 & $5.5294(1)$ & $5.4972(1)$ & $7.7873(2)$ & $236.71(1)$ \\
$298^{*}$ & $5.5307(1)$ & $5.4974(1)$ & $7.7883(2)$ & $236.80(1)$ \\
373 & $5.5341(1)$ & $5.4998(1)$ & $7.7919(2)$ & $237.16(1)$ \\
$473(P b n m)$ & $5.5404(1)$ & $5.5046(1)$ & $7.8004(2)$ & $237.89(1)$ \\
$473(R \overline{3} c)$ & $5.5407(7)$ & - & $13.321(2)$ & $354.15(8)$ \\
$573(P b n m)$ & $5.5481(2)$ & $5.5119(2)$ & $7.8117(3)$ & $238.89(2)$ \\
$573(R \overline{3} c)$ & $5.5473(2)$ & - & $13.3812(5)$ & $356.61(2)$ \\
673 & $5.5538(1)$ & - & $13.4202(3)$ & $358.48(1)$ \\
773 & $5.5591(1)$ & - & $13.4436(3)$ & $359.79(1)$ \\
873 & $5.5636(1)$ & - & $13.4676(3)$ & $361.02(1)$ \\
973 & $5.5689(1)$ & - & $13.4927(3)$ & $362.38(1)$ \\
1073 & $5.5741(1)$ & - & $13.5172(3)$ & $363.72(1)$ \\
1173 & $5.5793(1)$ & - & $13.5416(3)$ & $365.06(1)$ \\
\hline
\end{tabular}

"Data was collected immediately after high temperature diffraction.

in the temperature range of $700-950{ }^{\circ} \mathrm{C}$. This conductivity behavior corroborates stability of the sample in this temperature range found by diffraction data (Fig. 3).

Figure 5 presents oxygen content of $\mathrm{LaNi}_{0.4} \mathrm{Fe}_{0.6} \mathrm{O}_{3-\delta}$ composition depending on temperature $\left(700-950{ }^{\circ} \mathrm{C}\right)$ and oxygen partial pressure $(18-21000 \mathrm{~Pa})$. The highest oxygen non-stoichiometry $(\delta=0.016)$ is observed at the highest temperature $950{ }^{\circ} \mathrm{C}$ and the lowest oxygen partial pressure $18 \mathrm{~Pa}$. The slopes of the linear data versus $\log \left(p_{\mathrm{O}_{2}}\right)$ increase with temperature.

The conductivity of dense sample recalculated to theoretical density after Eq. (1) is shown in Fig. 6 as a function of oxygen partial pressure at different temperatures (a) and as a function of reciprocal absolute temperature at different oxygen partial pressures (b). The highest conductivity of about $160 \mathrm{~S} \cdot \mathrm{cm}^{-1}$ is found at $950{ }^{\circ} \mathrm{C}$ in air. At temperatures below $800{ }^{\circ} \mathrm{C}$, no influence of oxygen partial pressure on the conductivity is found (Figs. 6(a) and 6(b)). At temperatures above $800{ }^{\circ} \mathrm{C}$, the conductivity increases with oxygen partial pressure, which is typically for p-type oxide semiconductors.

The temperature dependences of conductivity have maxima, which are moved to higher temperatures with increasing oxygen partial pressure from $750{ }^{\circ} \mathrm{C}$ at $4 \mathrm{~Pa}$ 

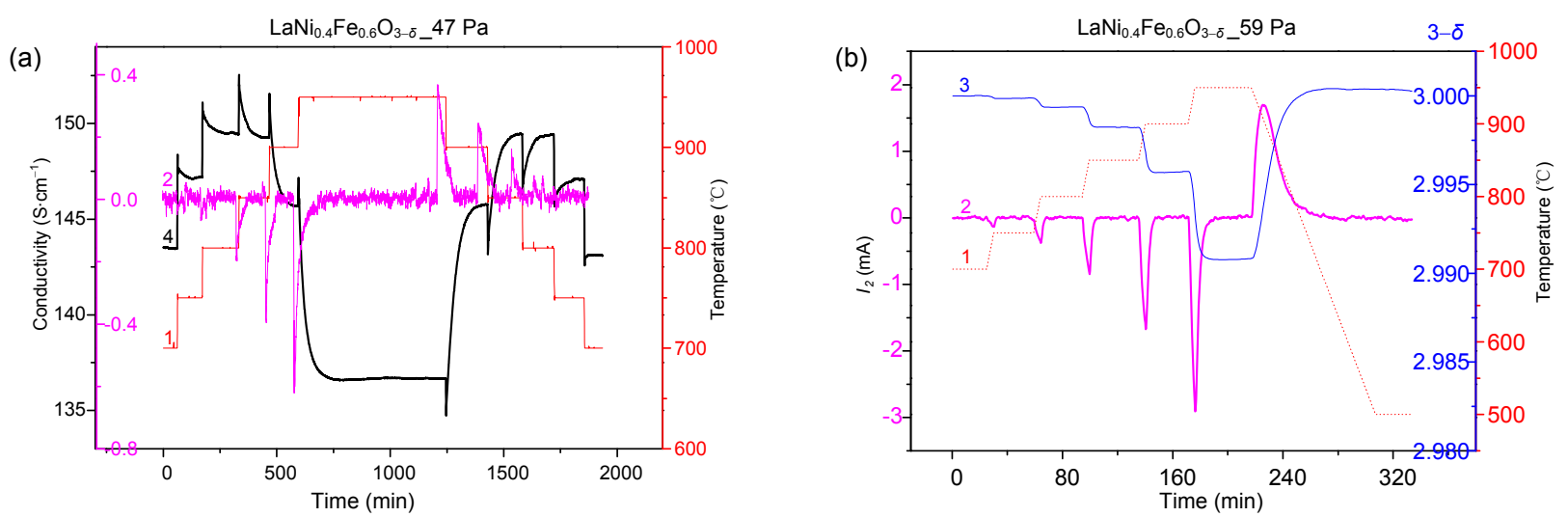

Fig. 4 Temperature of the sample (line 1), titration current in the cell 2 of ZiroxSystem device (line 2), oxygen content (line 3), and conductivity (line 4) of (a) $\mathrm{LaNi}_{0.4} \mathrm{Fe}_{0.6} \mathrm{O}_{3-\delta}$ ceramic samples and (b) $\mathrm{LaNi}_{0.4} \mathrm{Fe}_{0.6} \mathrm{O}_{3-\delta}$ powder measured during stepwise heating-cooling process in $\mathrm{Ar} / \mathrm{O}_{2}$ gas flow at $47 \mathrm{~Pa}$ and $59 \mathrm{~Pa}$, respectively.

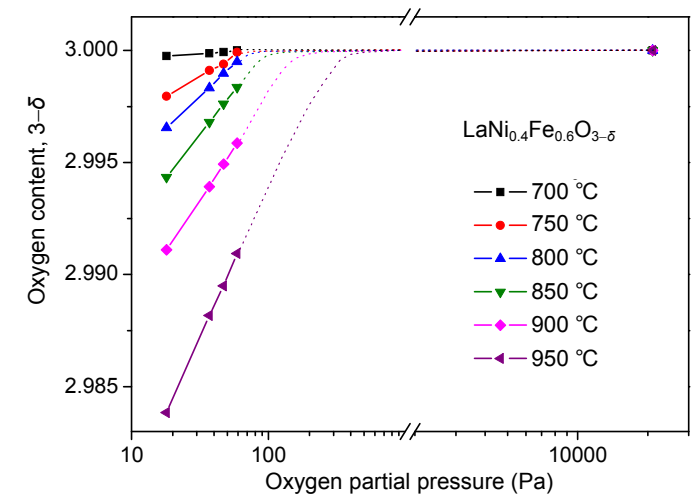

Fig. 5 Oxygen content of $\mathrm{LaNi}_{0.4} \mathrm{Fe}_{0.6} \mathrm{O}_{3-\delta}$ depending on temperature and oxygen partial pressure.

to $800{ }^{\circ} \mathrm{C}$ at $18 \mathrm{~Pa}, 850{ }^{\circ} \mathrm{C}$ at $59 \mathrm{~Pa}$, and over $950{ }^{\circ} \mathrm{C}$ in air (Fig. 6(b)). The transformation of the conductivity from semi-conducting to metallic type observed with increasing temperature above $700-850{ }^{\circ} \mathrm{C}$ could be understood with oxygen release from the sample, which increases with decreasing oxygen partial pressure and increasing temperature (Fig. 4). The conductivity along the $(-\mathrm{O}-\mathrm{Fe}(\mathrm{Ni})-\mathrm{O}-\mathrm{Fe}(\mathrm{Ni})-)$ chains in perovskite-type structure decreases due to the decrease of the concentration of charge carriers [22-24]. The carrier concentration decreases by charge compensation, if oxygen vacancies are formed.

\section{3 0xygen surface exchange and chemical diffusion coefficients}

Figure 7 shows the experimental and fitted data for normalized conductivity for the $\mathrm{LaNi}_{0.4} \mathrm{Fe}_{0.6} \mathrm{O}_{3-\delta}$ gas dense sample after a temperature jump from $850{ }^{\circ} \mathrm{C}$ to
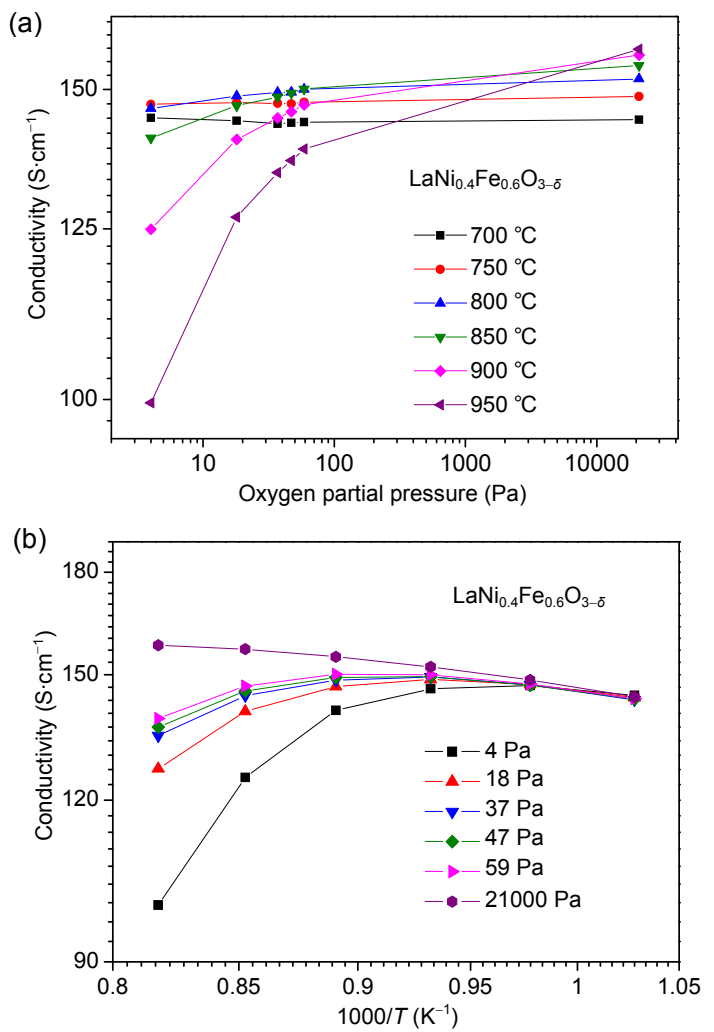

Fig. 6 Electrical conductivity of $\mathrm{LaNi}_{0.4} \mathrm{Fe}_{0.6} \mathrm{O}_{3-\delta}$ sample (a) versus oxygen partial pressure at different temperatures and (b) versus reciprocal absolute temperature at different oxygen partial pressures.

$900{ }^{\circ} \mathrm{C}$ at $59 \mathrm{~Pa}$. Clearly, good fit of the experimental data has been observed. This means that the model of relaxation of the sample after temperature jumps, described in Section 2.3, is reasonable for the investigated sample at the described experimental conditions, and the calculated values of oxygen surface 


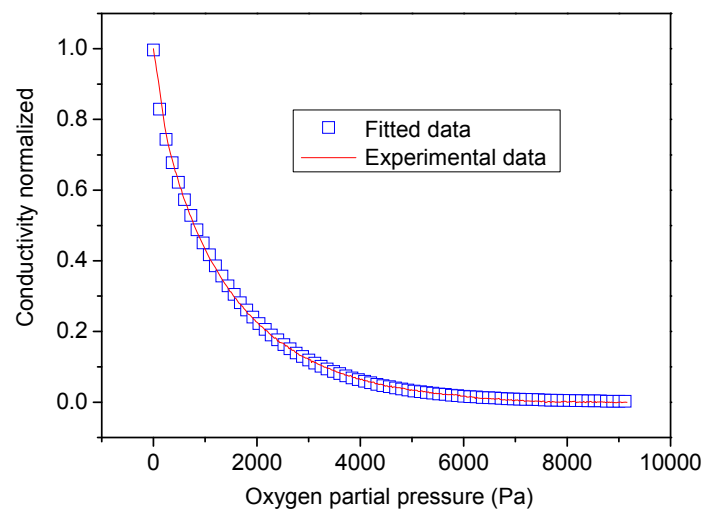

Fig. 7 Experimental and fitted data for normalized conductivity of the $\mathrm{LaNi}_{0.4} \mathrm{Fe}_{0.6} \mathrm{O}_{3-\delta}$ sample after stepwise change of the temperature from $850{ }^{\circ} \mathrm{C}$ to $900{ }^{\circ} \mathrm{C}$ in $\mathrm{Ar} / \mathrm{O}_{2}$ gas flow at $p_{\mathrm{O}_{2}}=59 \mathrm{~Pa}$.

exchange rate and chemical diffusion coefficients could be considered as reliable.

Temperature dependences of oxygen surface exchange and chemical diffusion coefficients are shown in Fig. 8. It is difficult to explain these data, because the dependences are not monotonous. Especially at $750-850{ }^{\circ} \mathrm{C}$, some anomalies in the coefficient values are observed. The measured weak temperature dependences of conductivity at $750-850{ }^{\circ} \mathrm{C}$ (maxima in Fig. 6(b)) are the possible reasons for the deviation of coefficients from the real values. It can be additionally considered that at temperature jumps in this temperature range, the conductivity maxima are situated between the initial and end temperatures of the sample. If this is the case, the relaxation model (Eq. (2)) can not provide absolutely correct values of oxygen chemical diffusion and surface exchange coefficients [25].

Despite of that, in the complete measured temperature range, the oxygen surface exchange coefficients determined by reduction modes are higher than those determined by oxidation modes and vary between $4 \times 10^{-6} \mathrm{~cm} \cdot \mathrm{s}^{-1}$ and $0.01 \mathrm{~cm} \cdot \mathrm{s}^{-1}$ (Figs. 8(a)-8(e)). In contrast to that, the chemical diffusion coefficients calculated at reduction modes are lower in comparison to those determined at oxidation modes, especially at high temperatures. It is possible that the lower oxygen vacancy concentration on the surface of the sample during reduction modes (jumps up from the lower temperatures) in comparison with oxidation modes (jumps down from the higher temperatures) serves as the reason for accelerated oxygen exchange kinetics.

These data disagree with the results determined for $\mathrm{La}_{1-x} \mathrm{Sr}_{x} \mathrm{Mn}_{1-y} \mathrm{Co}_{y} \mathrm{O}_{3 \pm \delta}$ by isotope exchange depth profile method at nominal oxygen pressure $1 \mathrm{~atm}$. Our measurements were carried out at more low oxygen concentration in gas phase and our sample had surely higher oxygen vacancy concentration. Maybe the high oxygen vacancy concentration in near-surface region of the sample results in the formation of neutral defect clusters of the type $\left(-\mathrm{B}-\mathrm{V}_{\mathrm{O}}-\mathrm{B}-\right)$. Such clusters, as shown by Van Roosmalen and Cordfunke [26], are not suitable for transport of oxygen ions, and thus reduce the concentration of "free" vacancies available for oxygen transport and exchange.

The chemical diffusion coefficients are varied in the range of $10^{-7}-10^{-4} \mathrm{~cm}^{2} \cdot \mathrm{s}^{-1}$ (Figs. $8(\mathrm{f})-8(\mathrm{j})$ ) and, in comparison with oxygen exchange coefficients, changed in the opposite direction depending on temperature jump modes. That can be understood by increasing oxygen diffusion mobility in $\mathrm{LaNi}_{0.4} \mathrm{Fe}_{0.6} \mathrm{O}_{3-\delta}$ composition with increasing oxygen vacancy concentration. The different behavior between the near-surface and volume regions of ceramic sample may be caused by different compositions of these regions, which are not analysed in this work. Sintering of mixed oxide ceramics can be accompanied by enriching of the near-surface regions of ceramics by separate cations and that can be the reason of different $k$ and $D$ values found for $\mathrm{La}_{0.6} \mathrm{Sr}_{0.4} \mathrm{Co}_{0.2} \mathrm{Fe}_{0.8} \mathrm{O}_{3-\delta}$ in different laboratories [27]. Our samples were sintered at $1600{ }^{\circ} \mathrm{C}$ and not polished after sintering before relaxation measurements.

The dependencies of oxygen exchange and diffusion parameters on temperature jump modes found for $\mathrm{LaNi}_{0.4} \mathrm{Fe}_{0.6} \mathrm{O}_{3-\delta}$ disagree with the results determined for analogous praseodymium-contained composition $\mathrm{PrNi}_{0.4} \mathrm{Fe}_{0.6} \mathrm{O}_{3-\delta}$ investigated previously [28]. The higher oxygen diffusion mobility in $\operatorname{PrNi}_{0.4} \mathrm{Fe}_{0.6} \mathrm{O}_{3-\delta}$ was observed during reduction processes and has been explained by the already known formation of high mentioned neutral defect clusters of the type $\left(-\mathrm{B}-\mathrm{V}_{\mathrm{O}}-\mathrm{B}-\right)$. Different chemical nature of lanthanum and praseodymium and also different crystal structures of $\mathrm{PrNi}_{0.4} \mathrm{Fe}_{0.6} \mathrm{O}_{3-\delta}(P b n m)$ and $\mathrm{LaNi}_{0.4} \mathrm{Fe}_{0.6} \mathrm{O}_{3-\delta}(R \overline{3} c)$ at comparable experimental conditions are evidently the reasons for different behavior of transport properties of these compounds depending of direction of temperature jumps.

\section{Conclusions}

$\mathrm{LaNi}_{0.4} \mathrm{Fe}_{0.6} \mathrm{O}_{3-\delta}$ shows phase stability in the 

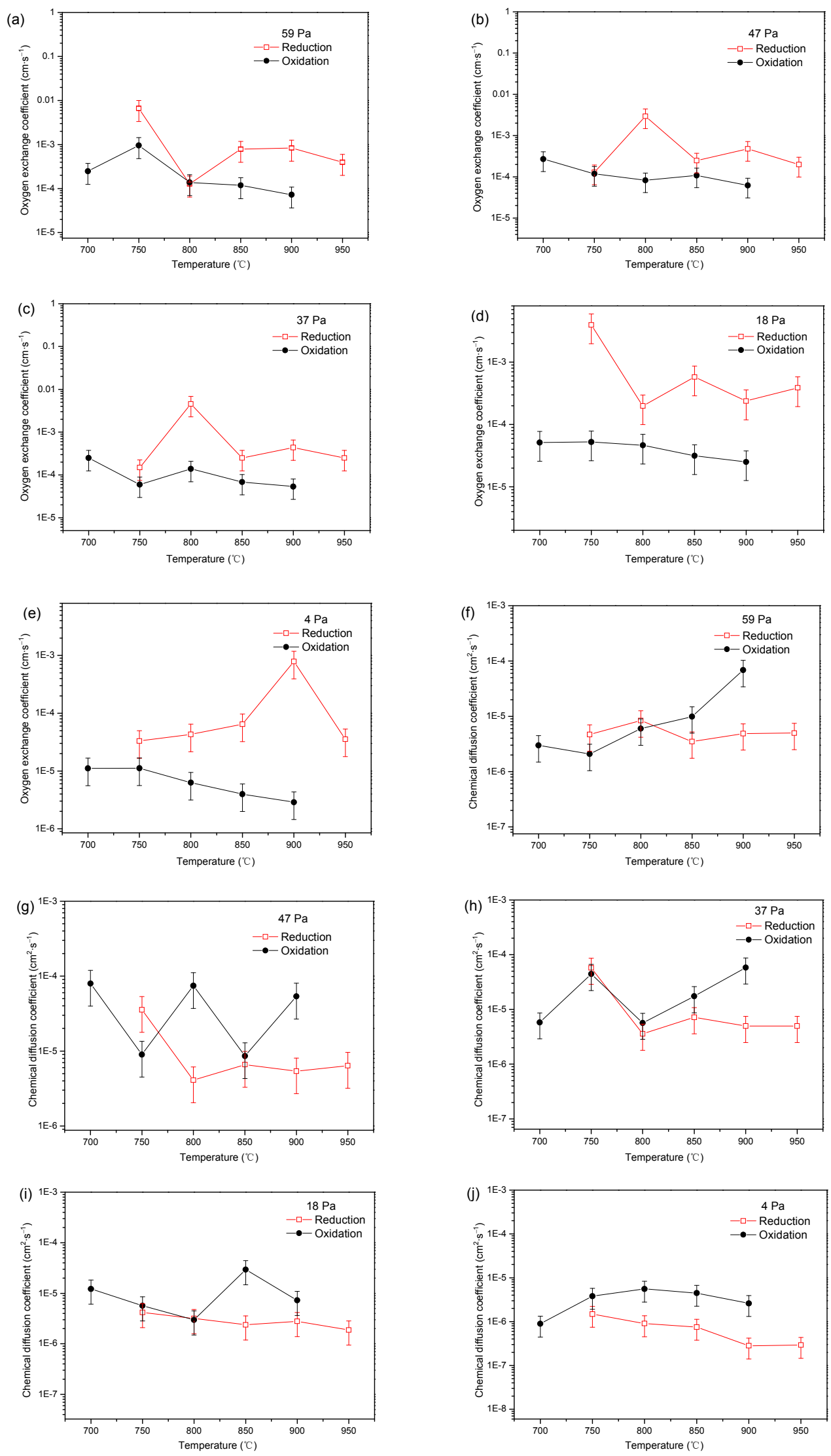

Fig. 8 Temperature dependences of (a)-(e) oxygen surface exchange and (f)-(j) chemical diffusion coefficients measured at different oxygen partial pressures. 
temperature range of $700-950{ }^{\circ} \mathrm{C}$ at oxygen partial pressures of 4-21000 $\mathrm{Pa}$. The reversible phase transformation $($ Pbnm $\leftrightarrow R \overline{3} c)$ occurs at $200-300{ }^{\circ} \mathrm{C}$ in air. Conductivity, oxygen content and relaxation parameters in region of existence of compound are investigated. The highest conductivity of about $160 \mathrm{~S} \cdot \mathrm{cm}^{-1}$ is found at $950{ }^{\circ} \mathrm{C}$ in air. The oxygen surface exchange coefficients depending on temperature, oxygen partial pressure and temperature jump modes are varied between $4 \times 10^{-6} \mathrm{~cm} \cdot \mathrm{s}^{-1}$ and $0.01 \mathrm{~cm} \cdot \mathrm{s}^{-1}$ and are higher for reduction processes in comparison with those determined at oxidation processes at the same temperatures. The chemical diffusion coefficients are varied in the range of $10^{-7}-10^{-4} \mathrm{~cm}^{2} \cdot \mathrm{s}^{-1}$ and in comparison with oxygen exchange coefficients are changed in opposite direction depending on temperature jump directions. In comparison with $\operatorname{PrNi}_{0.4} \mathrm{Fe}_{0.6} \mathrm{O}_{3-\delta}$ the different influence of treatment modes (oxidation/reduction) at the same temperatures on oxygen exchange and chemical diffusion coefficients is found.

\section{Acknowledgements}

The authors gratefully acknowledge the financial support of the European Union, the Government of Saxony, Germany (SAB Project 14252) and HASYLAB/DESY for X-ray diffraction measurements with synchrotron radiation (Project I-20090287).

Open Access: This article is distributed under the terms of the Creative Commons Attribution License which permits any use, distribution, and reproduction in any medium, provided the original author(s) and the source are credited.

\section{References}

[1] Atkinson A, Barnett S, Gorte RJ, et al. Advanced anodes for high-temperature fuel cells. Nat Mater 2004, 3: 17-27.

[2] Chiba R, Yoshimura F, Sakurai Y. An investigation of $\mathrm{LaNi}_{1-x} \mathrm{Fe}_{x} \mathrm{O}_{3}$ as a cathode material for solid oxide fuel cells. Solid State Ionics 1999, 124: 281-288.

[3] Zhen YD, Tok AIY, Jiang SP, et al. $\mathrm{La}(\mathrm{Ni}, \mathrm{Fe}) \mathrm{O}_{3}$ as a cathode material with high tolerance to chromium poisoning for solid oxide fuel cells. J Power Sources 2007, 170: 61-66.

[4] Orui H, Watanabe K, Chiba R, et al. Application of
$\mathrm{LaNi}(\mathrm{Fe}) \mathrm{O}_{3}$ as $\mathrm{SOFC}$ cathode. $J$ Electrochem $\mathrm{Soc}$ 2004, 151: A1412-A1417

[5] Millar L, Taherparvar $\mathrm{H}$, Filkin $\mathrm{N}$, et al. Interaction of $\left(\mathrm{La}_{1-x} \mathrm{Sr}_{x}\right)_{1-y} \mathrm{MnO}_{3}-\mathrm{Zr}_{1-\mathrm{z}} \mathrm{Y}_{z} \mathrm{O}_{2-d}$ cathodes and $\mathrm{LaNi}_{0.6} \mathrm{Fe}_{0.4} \mathrm{O}_{3}$ current collecting layers for solid oxide fuel cell application. Solid State Ionics 2008, 179: 732-739.

[6] Kostogloudis GCh, Tsiniarakis G, Ftikos Ch. Chemical reactivity of perovskite oxide SOFC cathodes and yttria stabilized zirconia. Solid State Ionics 2000, 135: 529-535.

[7] Chiba R, Yoshimura F, Sakurai Y. Extended abstracts of the 23rd Symposium on Solid State Ionics in Japan. 1997, 2A06: 91.

[8] Huijsman JPP, van Berkel FPF, Christie GM. Intermediate temperature $\mathrm{SOFC}-\mathrm{A}$ promise for the 21st century. J Power Sources 1998, 71: 107-110.

[9] Chen J, Wang S, Wen T, et al. Optimization of $\mathrm{LaNi}_{0.6} \mathrm{Fe}_{0.4} \mathrm{O}_{3-\delta}$ cathode for intermediate temperature solid oxide fuel cells. $J$ Alloys Compd 2009, 487: 377-381.

[10] Wang S, Kato T, Nagata $\mathrm{S}$, et al. Performance of a $\mathrm{La}_{0.6} \mathrm{Sr}_{0.4} \mathrm{Co}_{0.8} \mathrm{Fe}_{0.2} \mathrm{O}_{3}-\mathrm{Ce}_{0.8} \mathrm{Gd}_{0.2} \mathrm{O}_{1.9}-\mathrm{Ag}$ cathode for ceria electrolyte SOFCs. Solid State Ionics 2002, 146: 203-210.

[11] Wang S, van der Heide PAW, Chavez C, et al. An electrical conductivity relaxation study of $\mathrm{La}_{0.6} \mathrm{Sr}_{0.4} \mathrm{Fe}_{0.8} \mathrm{Co}_{0.2} \mathrm{O}_{3-\delta}$. Solid State Ionics 2003, 156: 201-208.

[12] Yasuda I, Hishinuma M. Electrical conductivity and chemical diffusion coefficient of Sr-doped lanthanum chromites. Solid State Ionics 1995, 80: $141-150$.

[13] Raj ES, Kilner JA, Irvine JTS. Oxygen diffusion and surface exchange studies on $\left(\mathrm{La}_{0.75} \mathrm{Sr}_{0.25}\right)_{0.95} \mathrm{Cr}_{0.5} \mathrm{Mn}_{0.5} \mathrm{O}_{3-\delta}$. Solid State Ionics 2006, 177: 1747-1752.

[14] Adler SB. Factors governing oxygen reduction in solid oxide fuel cell cathodes. Chem Rev 2004, 104: 4791-4844.

[15] Preis W, Bucher E, Sitte W. Oxygen exchange measurements on perovskites as cathode materials for solid oxide fuel cells. $J$ Power Sources 2002, 106: $116-121$

[16] Knapp M, Baehtz C, Ehrenberg H, et al. The synchrotron powder diffractometer at beamline B2 at HASYLAB/DESY: Status and capabilities. J Synchrotron Rad 2004, 11: 328-334.

[17] Vashook V, Vasylechko L, Zosel J, et al. Crystal structure and electrical conductivity of lanthanum-calcium chromites-titanates $\mathrm{La}_{1-x} \mathrm{Ca}_{x} \mathrm{Cr}_{1-y} \mathrm{Ti}_{y} \mathrm{O}_{3-\delta}(x=0-1, y=0-1) . J$ Solid State 
Chem 2004, 177: 3784-3794.

[18] Teske K, Ullmann H, Trofimenko N. Thermal analysis of transition metal and rare earth oxide system-gas interactions by a solid electrolyte-based coulometric technique. J Therm Anal 1997, 49: 1211-1220.

[19] Carter RE, Roth WL. Ionic conductivity and vacancy ordering in calcia stabilized zirconia. Report series 63-RL-3479M. General Electric Research Laboratory, Schenectady, NY, 1963.

[20] Yasuda I, Hishinuma M. Electrical conductivity and chemical diffusion coefficient of strontium-doped lanthanum manganites. J Solid State Chem 1996, 123: 382-390.

[21] Vashook V, Al Daroukh M, Ullmann H. Oxygen ion diffusion in perovskite-type oxides determined by permeation and by relaxation measurements. Ionics 2001, 7: 59-66.

[22] Petrov AN, Kononchuk OF, Andreev AV, et al. Crystal structure, electrical and magnetic properties of $\mathrm{La}_{1-x} \mathrm{Sr}_{x} \mathrm{CoO}_{3-y}$. Solid State Ionics 1995, 80: 189-199.

[23] Stevenson JW, Armstrong TR, Carneim RD, et al.
Electrochemical properties of mixed conducting perovskites $\mathrm{La}_{1-x} \mathrm{M}_{x} \mathrm{Co}_{1-y} \mathrm{Fe}_{y} \mathrm{O}_{3-\delta}(\mathrm{M}=\mathrm{Sr}, \mathrm{Ba}, \mathrm{Ca})$. J Electrochem Soc 1996, 143: 2722-2729.

[24] Kostogloudis GCh, Ftikos Ch. Structural, thermal and electrical properties of $\operatorname{Pr}_{0.5} \mathrm{Sr}_{0.5} \mathrm{Co}_{1-y} \mathrm{Ni}_{y} \mathrm{O}_{3-\delta}$ perovskite-type oxides. Solid State Ionics 1998, 109: 43-53.

[25] Yoo H-I, Lee C-E. Conductivity relaxation patterns of mixed conductor oxides under a chemical potential gradient. Solid State Ionics 2009, 180: 326-337.

[26] Van Roosmalen JAM, Cordfunke EHP. A new defect model to describe the oxygen deficiency in perovskite-type oxides. J Solid State Chem 1991, 93: 212-219.

[27] Cox-Galhotra RA, McIntosh S. Unreliability of simultaneously determining $k_{\text {chem }}$ and $D_{\text {chem }}$ via conductivity relaxation for surface-modified. Solid State Ionics 2010, 181: 1429-1436.

[28] Rebello J, Vashook V, Trots D, et al. Thermal stability, oxygen non-stoichiometry, electrical conductivity and diffusion characteristics of $\mathrm{PrNi}_{0.4} \mathrm{Fe}_{0.6} \mathrm{O}_{3-\delta}$, a potential cathode material for IT-SOFCs. J Power Sources 2011, 196: 3705-3712. 